\title{
CAULLIER, Joëlle, La Belle et la Bête. L'Allemagne des Kappelmeister dans l'imaginaire français (1890-1914)
}

\section{Christophe Duhamelle et Patrice Veit}

\section{OpenEdition}

\section{Journals}

Édition électronique

URL : http://journals.openedition.org/ifha/2056

DOI : 10.4000/ifha.2056

ISSN : 2198-8943

Éditeur

IFRA - Institut franco-allemand (sciences historiques et sociales)

Référence électronique

Christophe Duhamelle et Patrice Veit, «CAULLIER, Joëlle, La Belle et la Bête. L'Allemagne des

Kappelmeister dans l'imaginaire français (1890-1914) », Revue de l'IFHA [En ligne], Date de recension, mis en ligne le 01 janvier 1994, consulté le 22 septembre 2020. URL : http://journals.openedition.org/ifha/ 2056 ; DOI : https://doi.org/10.4000/ifha.2056

Ce document a été généré automatiquement le 22 septembre 2020.

(C)IFHA 


\title{
CAULLIER, Joëlle, La Belle et la Bête. L'Allemagne des Kappelmeister dans l'imaginaire français (1890-1914)
}

\author{
Christophe Duhamelle et Patrice Veit
}

1 Nouvelle venue, la collection " Transferts » présente un essai fort intéressant consacré à la vogue des chefs d'orchestre allemands auprès du public parisien entre la fin du XIXe siècle et la Première Guerre mondiale. Le regain de l'esthétique allemande en France à partir des années 1880 , le succès du concert symphonique, la Wagnérophilie qui s'installe dans les années 1890 , la consécration de la figure du chef d'orchestre qui concentre de plus en plus l'attention sont autant de facteurs qui contribuent au succès des premiers Kapellmeister. Entre 1894, date où, pour la première fois, un chef allemand est invité à la tête de l'Orchestre Colonne, et 1914, 18 Kapellmeister se succèdent à Paris et la presse parisienne se fait largement l'écho du passage, entre autres, des Felix Mottl, Arthur Nikisch, Felix Weingartner ou Richard Strauss.

2 L'originalité de l'ouvrage réside dans le fait que ces chefs allemands sont appréhendés comme une sorte de baromètre de la mentalité française face à l'Allemagne, à travers l'image de cette dernière qu'ils renvoient dans la société française à mesure que celleci, en regard, se forge sa propre identité. L'audience que connaissent ces Kapellmeister varie en fonction des modifications de l'ambiance française entre 1890 et 1914: au feu d'artifice des concerts où les chefs occupent la vedette et à l'enthousiasme des années 1894-1901 succèdent, entre 1905 et 1911 (l'époque de Tanger et d'Agadir), quelques apparitions de stars de la baguette (en particulier Felix Weingartner et Richard Strauss) lors de grands festivals qui finissent par se réduire exclusivement à quelques manifestations prestigieuses d'art lyrique dans les années 1911-1914, où les chefs allemands ne sont plus qu'un élément parmi d'autres du spectacle. L'afflux salué des Kapellmeister sera progressivement ressenti comme une sorte de menée impérialiste et les qualités de brillant et de virtuosité que le public admirait en eux seront bientôt tournées en griefs. Par le miroir des chefs allemands, meneurs d'hommes reflétant la 
puissance germanique, on voit donc la France basculer d'un cosmopolitisme pacifiste à un nationalisme belliqueux par différents dégradés.

3 C'est un jeu double, fait de fascination et de répulsion, que démonte cette étude sociopsychologique stimulante, complétée, en fin de volume, d'un certain nombre d'annexes (programmes des manifestations musicales allemandes à Paris, analyse des programmes en fonction des différentes oeuvres jouées ou recensement des orchestres dirigés à Paris par les Kapellmeister).

4 Christophe DUHAMELLE, Patrice VEIT 